\title{
Validade e Confiabilidade na Pesquisa Qualitativa em Administração
}

\author{
Fernando Gomes de Paiva Júnior ${ }^{1}$ \\ André Luiz Maranhão de Souza Leão ${ }^{2}$ \\ Sérgio Carvalho Benício de Mello ${ }^{3}$
}

\section{Resumo}

O uso da pesquisa qualitativa tem crescido na academia de Administração. No entanto, entende-se que para sua melhor utilização seja necessário discutir seus princípios de validade e confiabilidade. Com base nisto, este texto se inicia com uma discussão acerca de aspectos epistemológicos e éticos associados ao uso da pesquisa qualitativa. Depois, discutem-se os diferentes tipos de critérios de validade e confiabilidade pertinentes à pesquisa qualitativa. Finalmente, tais critérios são apresentados. Essa lógica é aplicada ao campo da Administração. Para concluir, chama-se a atenção para a relevância da presente discussão e destaca-se que esta seja fundamental para a credibilidade da pesquisa qualitativa no campo da Administração, uma vez que esse campo é dominado pelo paradigma positivista.

Palavras-chave: Pesquisa Qualitativa. Validade. Confiabilidade.

1 Professor Adjunto do Departamento de Ciências Administrativas - DCA da Universidade Federal de Pernambuco - UFPE e membro permanente do Programa de Pós-Graduação em Administração - PROPAD da Universidade Federal de Pernambuco - UFPE. Pesquisador do Grupo de Estudos e Pesquisa em Inovação, Tecnologia e Consumo (GITEC). End.: Av. Prof. Moraes Rego, 1235, Cidade Universitária, Recife - PE. CEP: 50670-901 - Brasil. E-mail: fernando.paivajr@ufpe.br

2 Professor Adjunto do Departamento de Ciências Administrativas - DCA da Universidade Federal de Pernambuco - UFPE e membro permanente do Programa de Pós-Graduação em Administração - PROPAD da Universidade Federal de Pernambuco - UFPE. Pesquisador do Grupo de Estudos e Pesquisa em Inovação, Tecnologia e Consumo (GITEC). Bolsista de produtividade em pesquisa do CNPq. End.: Av. Prof. Moraes Rego, 1235, Cidade Universitária, Recife-PE. CEP: 50670-901 - Brasil. E-mail: andre.leao@pq.cnpq.br. 3 Professor Associado do Departamento de Ciências Administrativas - DCA da Universidade Federal de Pernambuco - UFPE e membro permanente do Programa de Pós-Graduação em Administração - PROPAD da Universidade Federal de Pernambuco UFPE. Pesquisador do Grupo de Estudos e Pesquisa em Inovação, Tecnologia e Consumo (GITEC). Bolsista de produtividade em pesquisa do CNPq. End.: Av. Prof. Moraes Rego, 1235, Cidade Universitária, Recife - PE. CEP: 50670-901 - Brasil. E-mail: sergio. benicio@pq.cnpq.br.

Artigo recebido em: 27/08/2010. Aceito em: 15/08/2011. Membro do Corpo Editorial Científico responsável pelo processo editorial: Eduardo Damião da Silva.

(c) (i) $\left(\right.$ EY $\bigodot_{\mathrm{EY}}$ Esta obra está sob uma Licença Creative Commons Atribuição-Uso. 


\section{Introdução}

O reconhecimento de que, nas relações humanas, a "realidade" ocorre dentro de contextos históricos e é construída socialmente tem levado parte das pesquisas sociais e humanas à utilização de métodos qualitativos (GUBA; LINCOLN, 2005). Isso contribui para que a análise qualitativa, em pouco mais de um século de desenvolvimento, obtenha espaço na academia, justamente por se configurar como uma alternativa à mensuração, já que nem todos os problemas de pesquisa passam por esta abordagem (DENZIN; LINCOLN, 2005). Contudo, são vários os críticos da pesquisa qualitativa, seja por parte de pesquisadores afeitos à chamada "ciência normal", que defendem o princípio de que qualquer fenômeno precisa ser medido para ter utilidade, seja porque muitos questionam seus procedimentos, segundo eles, pouco claros, que abre um espaço para o "vale tudo" na análise (CHIZZOTTI, 2006; DENZIN; LINCOLN, 2005).

No que se refere a procedimentos analíticos, a pesquisa qualitativa não utiliza modelos matemáticos e/ou de aplicações estatísticas, mas da interpretação de textos, sons, imagens e até de linguagem não verbal (GUBA; LINCOLN, 2005). Nesse sentido, o que se faz necessário observar é que tanto a condescendência com o chamado "vale tudo" quanto a quantificação exacerbada - "o meio pelo meio" - podem conduzir a duas posições igualmente indesejáveis (GASKELL;BAUER, 2005).

Na medida em que a pesquisa qualitativa desenvolve uma reflexão crítica e um saber acumulado, é preciso que seus pesquisadores deixem de abordar critérios implícitos para avaliar e guiar pesquisas, ou seja, que não mais deixem tais critérios subentendidos e passíveis de não serem percebidos ou compreendidos, para adotarem critérios e processos de investigação mais explícitos, que possibilitem a compreensão e a replicação do estudo. São as concepções manifestas da boa prática de pesquisa gerarão a credibilidade externa e a legitimação para o estudo qualitativo, concebido, justamente devido a tais critérios "implícitos", como obscuro e esotérico, pela ciência normal (CLEGG; HARDY, 1999).

Dentro dessa discussão, vale destacar que a objetividade de um estudo qualitativo é avaliada em termos da validade e da confiabilidade de suas observações. Nesse sentido, entende-se como validade a confiança com que se podem tirar conclusões corretas de uma análise; como confiabilidade entende-se 
a consistência com que um procedimento de pesquisa irá avaliar um fenômeno da mesma maneira em diferentes tentativas (GASKELL; BAUER, 2005; KIRK; MILLER, 1986). Contudo, a pesquisa qualitativa tem seus próprios critérios de rigor científico que asseguram a legitimidade dos dados gerados em sua utilização (FLICK, 2008).

$\mathrm{Na}$ Administração, o crescimento que se vê do uso da pesquisa qualitativa é gradual, mas contínuo, apresentando ao campo novos caminhos investigativos em meio ao paradigma ainda dominante da quantificação (BOEIRA; VIEIRA, 2010). No entanto, são poucos - ainda que existentes - os esforços de nossa academia em relação ao desenvolvimento embasado da pesquisa qualitativa, o que é mais evidente em relação aos aspectos relativos à sua qualidade - ou, em outras palavras, aos seus aspectos de validade e confiabilidade (GODOI; BALSINI, 2010).

Sendo assim, o presente trabalho tem o objetivo de discutir que critérios a análise qualitativa tem utilizado para garantir tal rigor e qualidade na pesquisa. Além disso, também serão discutidas questões referentes à escolha do método qualitativo, fundamentais no andamento de tal procedimento, bem como a relevância da ética nos critérios de confiabilidade e validade da pesquisa qualitativa.

\section{Considerações Gerais}

Antes de abordar especificamente questões relativas à validade e à confiabilidade de pesquisa, é crítico que questões relativas à orientação epistemológica e à ética de um estudo qualitativo sejam pensadas, pois as posturas adotadas em relação a esses critérios irão nortear todo o esforço investigativo, impactando fortemente a legitimidade de uma pesquisa.

\subsection{Orientação Epistemológica}

A epistemologia se distingue de uma metodologia abstrata porque busca assimilar a lógica do erro para construir a lógica da descoberta da verdade como polêmica contra o erro e como esforço para submeter as verdades aproximadas da ciência e os métodos que ela utiliza a uma retificação metodológica e permanente. Desse modo, o processo do conhecimento científico vai se tornando 
um desafio de aproximação que transita de uma legitimidade menor para uma maior (BRUYNE; HERMAN; SCHOUTHEETE,1991).

A plausibilidade epistemológica do problema de pesquisa é um critério de cientificidade levantada ao conceber o que pode ser observável no fenômeno como premissa fundamental do estado de investigação. Oliva (1990) chama a atenção para o vínculo existente entre essa questão com a relevância do estudo denominada por ele de significa atividade cognitiva e nos alerta para saber o que pode ser expresso como sentido fatual, equivalente a indicar as condições necessárias e plausíveis a serem satisfeitas por enunciados que aspirem à condição de científicos. Bryman (2000) contrapõe o argumento anterior ao asseverar que boa parte dos enunciados não é verificável empiricamente - $e$, aliás, a razão se ser deles não é se confrontar com fatos -, e acrescenta que esta concepção empiricista de epistemologia pode chegar a arruinar a sua fecundidade, uma vez que nada deve ser apenas rigor, mas polêmica e crítica.

De fato, deve-se atentar para a observação de Castro (1977) quanto à questão da verificabilidade ter sido superada com o tratamento que neopositivistas como Popper (2000) deu ao conhecimento científico em torno da falsificabilidade ou refutabilidade, e parece existir uma convergência prática em torno desse segundo princípio, uma vez que para o fenômeno ser factual ou científico, o enunciado pode ser falsificável por ser possível imaginar uma situação em que ele não seja verdadeiro ou válido.

\subsection{A Questão Ética no Tratamento e na Contribuição do Estudo Qualitativo}

Merrian (1998) suscita questões éticas pertinentes que devem ser consideradas pelo pesquisador ao refletir se em nome da clareza e da transparência do estudo podem ser manifestados aspectos particulares ou mesmo ritos sacralizados pelo habitus do sujeito pesquisado, que poderiam vir a ser profanados se trazidos a público ou expostos de forma indevida.

Wiesenfeld (2000) corrobora essa visão, ao propor um debate sobre a questão da dignidade do pesquisado. Existe certo grau de perigo em desenvolver teorias e práticas com implicações importantes para a vida das pessoas estudadas e, que, por fim, terminam por não desfrutar de nenhum conhecimento. Em muitas situações, a pesquisa assume uma abordagem que leva à relação entre o sujeito que sabe (o pesquisador) iluminando o que não sabe. Nessa 
relação confusa e assimétrica, o pesquisador tem uma grande responsabilidade por assumir que pode falar pelo outro e interpretar de forma acurada o seu mundo e a sua vida.

\section{A Questão da Validade e da Confiabilidade na Pesquisa Científica}

Na pesquisa qualitativa, os critérios de validade e de confiabilidade assumem aspectos particulares. Isso se deve a algumas de suas características. Uma delas diz respeito ao fato de que a pesquisa qualitativa é sempre, em alguma instância, de caráter interpretativo. Com isso, a subjetividade do pesquisador está presente em todo o desenvolvimento da pesquisa. Por outro lado, a investigação qualitativa também assume pelo menos certo grau de indução, que pode chegar à sua forma mais pura, despojada de teoria e sem a formulação de hipóteses, mas permanecendo aberta à descoberta, mesmo quando se utiliza de um quadro teórico prévio, uma vez que este não será operado no nível de variáveis (LEÃO; MELLO; VIEIRA, 2009; RISJORD, MOLONEY, DUNBAR, 2001).

Além disso, a pesquisa qualitativa apresenta características operacionais que resultam num número pequeno de unidades de amostra, cujo critério é descrito como reconhecendo a existência de intencionalidade; num conteúdo composto de descrições detalhadas de situações relativas aos dados coletados do sujeito em análise com citações objetivas sobre suas experiências, atitudes, hábitos, credos e pensamentos; e, finalmente, numa contextualização de eventos, pessoas, interações e observações de comportamento. Para isso cabe o registro sistemático das constatações de passagens de documentos, correspondências e o estudo de situações peculiares relativas ao fenômeno em observação (LEININGER, 1994).

A validade se refere à capacidade que os métodos utilizados numa pesquisa propiciam à consecução fidedigna de seus objetivos. Na tradição qualitativa a validade tende a ser observada nos seguintes aspectos: validade aparente, que se refere a quando um método de pesquisa produz o tipo de informação desejado ou esperado; validade instrumental, que procura a combinação entre os dados fornecidos por um método de pesquisa e aqueles gerados por algum procedimento alternativo, que é aceito como válido; e validade teórica, que 
se refere à legitimidade dos procedimentos da pesquisa em termos de teoria estabelecida (KIRK; MILLER, 1986).

A confiabilidade, por sua vez, a refere-se à garantia de que outro pesquisador poderá realizar uma pesquisa semelhante e chegará a resultados aproximados. Na pesquisa qualitativa, tende a ser observada nos seguintes aspectos: confiabilidade quixotesca, que se refere às circunstâncias em que um único método de observação mantém uma medida contínua; confiabilidade diacrônica, que se refere à estabilidade de uma observação através do tempo; e confiabilidade sincrônica, que se refere à similaridade de diferentes observações dentro de um mesmo período de tempo (KIRK; MILLER, 1986).

\section{Critérios de Qualidade em Pesquisas Qualitativas}

Entende-se por critérios de qualidade na pesquisa qualitativa aqueles que a asseguram validade e confiabilidade. Alguns destes critérios têm função apenas na validade e outros apenas na confiabilidade da pesquisa, mas existem aqueles que afetam tanto um aspecto quanto o outro. A seguir serão apresentados os principais critérios de validade e confiabilidade, indicando em que aspectos eles atuam, os quais são sumarizados na Tabela 1.

Tabela 1: Critérios de validade e confiabilidade na pesquisa qualitativa

\begin{tabular}{|l|c|c|}
\hline \multicolumn{1}{|c|}{ Critério } & Validade & Confiabilidade \\
\hline Triangulação & $\mathrm{X}$ & $\mathrm{X}$ \\
\hline Reflexividade & & $\mathrm{X}$ \\
\hline Construção do corpus de pesquisa & $\mathrm{X}$ & $\mathrm{X}$ \\
\hline Descrição clara, rica e detalhada & $\mathrm{X}$ & $\mathrm{X}$ \\
\hline Surpresa & $\mathrm{X}$ & \\
\hline Feedback dos informantes (validação comunicativa) & $\mathrm{X}$ & $\mathrm{X}$ \\
\hline
\end{tabular}

Fonte: Elaborado pelos autores deste artigo 


\section{Triangulação}

A triangulação é um modo de institucionalização de perspectivas e métodos teóricos, buscando reduzir as inconsistências e contradições de uma pesquisa (GASKELL; BAUER, 2005). A técnica contribui tanto por meio de validade quanto de confiabilidade, compondo um quadro mais evidente do fenômeno por meio da convergência, conforme Patton (2002). Nesse sentido, Jick (1979) afirma que a triangulação é uma estratégia de pesquisa de validação convergente tanto de métodos múltiplos quanto de multi tratamento dos dados relativos a um mesmo fenômeno.

A metáfora da triangulação advém da navegação e da estratégia militar que consistiam em utilizar múltiplos pontos de referência para localizar uma posição exata do objeto. Tal princípio tem base também na geometria, que demonstra que os pontos de vista múltiplos permitem uma maior precisão. Assim, de forma análoga, os pesquisadores de estudos organizacionais podem aperfeiçoar seus julgamentos ao coletar diferentes tipos de dados e interpretações sobre o mesmo fenômeno (JICK, 1979).

Denzin (1978) sugere a existência de quatro diferentes tipos de triangulação, por meio de múltiplas e diferentes fontes, pesquisadores, métodos $e$ teorias. Indubitavelmente, o primeiro dos modos (fontes) é o mais amplamente difundido $e$ o que quase sempre se pensa quando se aborda o assunto triangulação. Creswell (2010) recomenda o uso de distintas fontes de informação. Nesse sentido, Merrian (1998) sugere que diferentes fontes, tais como entrevistas com gerentes de distintos níveis hierárquicos e diferentes tipos de técnicas de coleta de dados, como entrevistas e observações sobre determinado caso, podem enriquecer sua compreensão sobre o fenômeno estudado.

Outra abordagem importante é a utilização de mais de um pesquisador no processo. Nesse aspecto, Creswell (2010) sugere a alocação de uma pessoa distinta juntamente com o pesquisador para acompanhar os relatos e fazer perguntas aos entrevistados, bem como a convocação de um auditor externo para acompanhar o processo da pesquisa $e$ as conclusões do estudo, enquanto Merrian (1998) sugere que sejam utilizados analistas distintos, como colegas do pesquisador realizando a recodificação das transcrições das entrevistas.

Contudo, parece haver uma forte ênfase na triangulação quanto ao método. Risjord, Moloney e Dunbar (2001) comentam que a triangulação metodológica corresponde ao uso de dois ou mais distintos tipos de métodos em 
uma única linha de investigação. Jick (1979) aponta que os campos qualitativo e quantitativo devem ser utilizados de forma complementar e não como rivais. Merrian (1998) argumenta que o uso de perspectivas tanto qualitativas quanto quantitativas de abordagem de pesquisa, mesmo que divergentes na condução de processos perceptivos do fenômeno podem enriquecer sua compreensão de um dado fenômeno.

Nesse sentido, todavia, não existe um consenso. Alguns pesquisadores (os blending researchers) assumem posturas de integração dos métodos, os quais em conjunto podem produzir resultados de forma mais consistente que se estivessem adotando um único método (RISJORD; MOLONEY; DUNBAR, 2001). Críticos a essa visão argumentam que métodos qualitativos e quantitativos são baseados em pressupostos profundamente diferentes com relação ao objeto estudado, logo devem permanecer independentes, já que a adoção desses métodos não proporcionaria a confirmação de um com relação ao outro. Tais críticas são feitas por pesquisadores separatistas (os building blocks researchers), que advogam a favor da divisão natural entre os tipos de métodos e as teorias (RISJORD; MOLONEY; DUNBAR, 2001). Os teóricos separatistas argumentam que a profundidade e a natureza das diferenças entre os métodos qualitativo $e$ quantitativo os tornam incomensuráveis e defendem que a triangulação deve ser utilizada para fornecer visões complementares sobre um mesmo fenômeno.

No campo de estudos organizacionais, a pesquisa de Rice (2002) ilustra a aplicação de métodos múltiplos num estudo de caso que explora a assistência empresarial proporcionada pelos gerentes das incubadoras de base tecnológica aos empreendedores de alta tecnologia em Austin, Texas. Por meio de uma produção conjunta e diádica desenvolvida no ambiente das incubadoras, foi aplicada inicialmente uma survey detalhada junto aos primeiros e se utilizou um instrumento análogo junto aos segundos; depois houve a necessidade de se investigar aspectos ainda incompreendidos sobre a forma de assistência dos gerentes em relação aos empreendedores comunitários da incubadora e assim foram realizadas entrevistas em profundidade junto aos jovens empresários incubados.

O estudo desenvolvido por Munk, Munck e Souza (2011), relacionado à gestão por competências, objetiva avaliar um modelo de gestão de pessoas articulado por competência implementadas há mais de dez anos na empresa Alfa Telecon. Nesse estudo, os autores utilizam o sistema de triangulação como premissa metodológica de validação e legitimação para verificar a aplicação do 
modelo proposto por Markus, Cooper-Thomas e Allpress (2005). A estratégia de pesquisa consistiu no estudo de caso descritivo, no qual as informações foram consolidadas a partir de dados advindos de documentos, relatórios de gestão e entrevistas em profundidade. No final, constatou-se que o referido modelo apresenta fragilidades quanto a sua operacionalização, em função de aspectos como a linguagem utilizada não acessível para a maioria e, a partir disso, foram criadas expectativas na equipe que não puderam ser cumpridas. $\mathrm{O}$ tempo de maturação necessário para a compreensão do modelo foi insuficiente e que houve interpretações diferentes do modelo por parte dos das fontes essenciais para a pesquisa, tais como o consultor do projeto, funcionários, gerentes, diretores e o presidente da empresa. Isso, inclusive, no que diz respeito à orientação do modelo para contratações, promoções, remuneração e desenvolvimento causa mais confusão que orientação aos gestores. Em suma, a avaliação de modelos de competência a partir desse tipo de critério de validação pode auxiliar na aproximação entre premissas, ações e resultados relacionados à implantação, operacionalização e implantação nas empresas.

\subsection{Reflexividade}

A reflexividade é um critério de confiabilidade e diz respeito ao antes e ao depois do acontecimento, gerando transformação no pesquisador, uma vez que vai se tornando uma pessoa diferente por considerar as inconsistências do estudo ao longo do processo permanente de realização. Trata-se de se voltar ao processo investigativo tendo em vista suas possibilidades não apenas a partir do pesquisador, mas devido ao informante, à audiência e ao próprio texto (JOY et al., 2006). Assim, o "sujeito", historicamente fazedor da ação social, contribui para significar o universo pesquisado exigindo uma constante reflexão e reestruturação do processo de questionamento do pesquisador. A constante autorreflexão do pesquisador, portanto, é fundamental para evitar vieses interpretativos (CRESWELL, 2010).

No campo da Administração da era pós-burocrática, o teor reflexivo na investigação se projeta no âmbito da empresa por meio de abordagens de pesquisas que enfatizam a adoção de técnicas de diálogo e de apreciação evocadas por meio de conversações que resgatam o cultivo pelo espírito apreciativo voltado para a melhoria da qualidade de vida, a ligação desse espírito com a técnica e pela própria reflexividade. Assim, as abordagens de pesquisa 
que seguem essa linha de ação demonstram a tendência reflexiva tanto do pesquisador quanto do sujeito analisado, ao descobrir novos padrões e combinações de sentimentos, pensamentos e ações emergentes nas interações conversacionais não antes identificados no plano interativo das organizações (BARGE; OLIVER, 2003).

Numa pesquisa realizada com sete assessorias de Comunicação, no Estado de Goiás, de organizações públicas e privadas, dos primeiro, segundo e terceiro setores, atuantes em áreas como, hotelaria, esporte, governo, instituições sem fins lucrativos, Tuzzo e Mainieri (2011) desenvolveram um estudo com o objetivo de conhecer e analisar as assessorias de Comunicação de organizações do Estado de Goiás. Na pesquisa, os pesquisadores tiveram certo grau de reflexividade desde a definição do roteiro, de entrevista, da seleção das organizações a serem pesquisadas, no critério de seleção dos profissionais que seriam entrevistados e, principalmente, na relação da pesquisa empírica e teórica. Esse olhar vigilante lhes garantiu a apreensão do discurso científico, com a análise dos resultados e da metodologia da pesquisa empírica, colocados em reflexão com fim de se apontar rumos essenciais na produção do conhecimento científico no âmbito da Comunicação Organizacional. Os estudiosos, portanto, reconheceram que a reflexão constante permitiu ver que a pesquisa como fonte de transformação de discursos teóricos em constantes ajustes, reformas e aplicação, de modo a se gerar consistência na aproximação entre os mundos da academia e do trabalho.

\subsection{A Construção do Corpus de Pesquisa}

A construção do corpus é critério tanto de confiabilidade quanto de validade. É equivalente funcional à amostra representativa e ao tamanho da amostra, porém com o objetivo distinto de maximizar a variedade de representações desconhecidas.

O tamanho da amostra não se revela tão importante na construção do corpus, contanto que haja evidência de saturação dos dados. Quando não surgem mais relatos inusitados no processo de coleta de dados da pesquisa, recomenda-se o critério de finalização dessa coleta por meio da saturação das respostas das entrevistas, uma vez que os discursos não constituem contribuições adicionais significativas para as análises de dados e conclusões do estudo, em conformidade com Minayo (2010). A autora comenta que os entrevistados exercitam uma relação intensa com o pesquisador, decorrendo daí uma cons- 
trução de conhecimento comparável à realidade concreta, já concebida em hipóteses e pressupostos teóricos.

Ao buscar entender como pode o empreendedor transformar e compartilhar conhecimento especializado para o desenvolvimento do produto empreendedor de acordo com os níveis de especialização das equipes que atuam numa empresa de base tecnológica, Burns, Acar e Datta (2011) constroem o corpus do estudo utilizando métodos mistos de validação para compensar o fato de não se ter alcançado a saturação desejada, o que permitiu a obtenção de dados suficientes para fundamentar a parte analítica do estudo. Com a aplicação de triangulação múltipla de dados, por exemplo, conseguem um corpus consistente que garante informações contextuais, transcrições de entrevistas e conteúdos de questionário direcionado aos participantes. Nos casos de informações conflitantes entre as fontes, realizaram entrevistas de acompanhamento (follow-up interviews) com o gestor de projeto, de modo a deixar o processo final de compartilhamento de conhecimento suficientemente robusto. Os autores constatam que o ato de prover a credibilidade das fontes de forma integrada facilita a transferência de conhecimento para beneficiários de outros níveis de especialização em desenvolvimento de produto de empresas empreendedoras.

No estudo de Anna e Daryl (2011) sobre o uso de técnicas de marketing de relacionamento no setor de festivais musicais, o foco foi o de fornecer uma investigação sobre as técnicas de marketing de relacionamento utilizadas no setor de festivais musicais no Reino Unido. Nesse esforço, os autores buscavam identificar os as formas de relacionamento mais frequentes entre consumidores e patrocinadores e as técnicas de comunicação de marketing mais utilizadas pelos organizadores dos festivais. Os autores realizaram cinco entrevistas no total, esse número foi suficiente para que eles pudessem obter um conhecimento transversal entre as sessões de festivais, tanto de ethos como de tamanho distinto. Isso permitiu que os pesquisadores tivessem opiniões de pontos de vista diferenciados quanto às várias categorias de festas, como também o volume de informações do estudo foi adequado devido à riqueza dos dados avaliados após as entrevistas, fato que permitiu a saturação teórica para as intenções da pesquisa. 


\subsection{Descrição Clara, Rica e Detalhada}

Weber diz-nos que nas ciências sociais o que realmente interessa é o estudo dos fenômenos inteligíveis, cuja compreensão empática constitui tarefa do tipo especificamente diferente daquelas que a ciência natural se põe a executar. Assim, é tarefa do pesquisador realizar uma análise objetiva dos fatos sociais, independentemente da atividade humana ser de caráter subjetivo (GIDENS, 2000); logo, a descrição rica e detalhada será critério tanto de confiabilidade quanto de validade.

A clareza nos procedimentos é um critério de confiabilidade que diz respeito à boa documentação, à transparência e ao detalhamento de exposição dos nos procedimentos na busca e na análise dos resultados. O importante é gerar condições para que outros pesquisadores possam reconstruir o que foi realizado em cenários de pesquisa diferentes.

Nesse sentido, cabe ao pesquisador proporcionar suficiente descrição do contexto social do cenário da pesquisa e dos sujeitos analisados e das fases de sua elaboração para que os leitores fiquem aptos a determinar a proximidade de suas situações com o cenário relatado na pesquisa e até se descobertas podem ser transferíveis (MERRIAN, 1998), não obstante corresponder ao cuidado da inclusão de descrições densas dos participantes e do contexto do estudo. Essa prática é denominada transferibilidade na pesquisa qualitativa e desempenha função semelhante à da validade interna e externa dos estudos quantitativos.

É imperativo num estudo qualitativo se desenvolver uma noção de contexto do sujeito que atua num intercâmbio direto com seu ambiente natural e se estabelece pela mediação das características particulares da sociedade a que pertence, assim quando se pretende estudar a evolução da sociedade humana é necessário partir do exame empírico dos processos concretos da vida social que constituem condição sine qua non da existência humana (GIDENS, 2000).

A utilização de uma estratégia de pesquisa de base fenomenológica poderá prover as bases de compreensão do cotidiano, valores, atitudes e comportamentos de dirigentes no dia a dia das organizações, ao buscar seus significados e elementos estruturais postos entre parênteses ao se examinar o conhecimento e reflexão prática oriundos do senso comum (HOLSTEIN; GUBRIUM, 2005). Portanto, a compreensão de como o empresário vivencia experiências no âmbito de espaços institucionais e como usa tecnologias com alto valor agregado num cenário hostil e competitivo pode constituir uma base sugestiva de investigação. 
Booth e Segon (2009) discutem a natureza da pesquisa-ação contemporânea como suporte de descrições densas (thick description) para a prática de desenvolvimento gerencial num programa de pesquisa em educação, usando uma abordagem de investigação cooperativa para lideranças e desenvolvimento de prática de gerencial. No estudo com um grupo de 25 participantes do programa, os autores utilizaram métodos de reflexão e compreensão com respeito à experimentação de novos conceitos, ferramentas e técnicas. O estudo contou com o método de descrição rica e detalhada de eventos e experiências dos participantes do programa e foram capturados nos seus relatos um conjunto de reflexões e apresentações que compuseram a coleta e análise de dados da pesquisa. Essas descrições densas contaram com o apoio de registros diários das sessões de aprendizagem, conversas entre os participantes e pesquisadores, além das trocas de e-mails, gerando um processo dialético de absorção de dados e servindo de suporte comprobatório para as mudanças na prática de liderança e gestão experimentadas pelos participantes.

\subsection{A Surpresa como Contribuição à Teoria e ao Senso Comum}

A surpresa é um critério de validade na pesquisa qualitativa e tem uma importância para essa tradição tanto no que diz respeito à descoberta de evidências inspiradoras a novas formas de pensamento sobre determinado tema, quanto à mudança de mentalidade já cristalizada em torno do fenômeno, padrões esses carentes de serem revistos ou aprofundados sob diferentes prismas para a teoria, para o método ou mesmo para o conhecimento popularmente difundido na sociedade.

O estudo de Ogbor (2000) com respeito aos efeitos do controle ideológico sobre discurso e práxis empreendedora ilustra essa preocupação, ao criticar trabalhos publicados em revistas acadêmicas utilizando metodologias prevalentemente funcionalistas, cujos resultados são permeados por discursos de apologia e mitificação a tipos empreendedores característicos com o seguinte perfil: masculino, de cor branca e oriundo de países ricos, quando investigações de gênero ou mesmo de minorias sociais geram insights ricos e inusitados que poderão causar novas impressões que servem de riqueza nas áreas temáticas relativas à gestão empreendedora. 
Num estudo de caso na busca de soluções inovadoras entre as práticas de gerenciamento de projetos vis-à-vis a adequação da estrutura $e$ das competências organizacionais em uma empresa da cadeia produtiva do setor automobilístico, Rabechini et al. (2011) acabaram descobrindo que os fatores relacionados à falta de memória técnica, ao desenvolvimento gerencial e ao custo da estrutura organizacional num cenário de baixas competências individuais, das equipes e da organização representam dados inusitados que geram possibilidades de solucionar problemas de gestão com mudanças na cultura existente entre as atividades de rotina e de projetos.

$O$ pesquisador necessita que os entrevistados lhe relatem suas experiências, suas compreensões, seus sentimentos e suas impressões, de modo a poder caminhar na busca de indicações do que constitui de fato a visão que se tem do fenômeno indutor do conflito a partir de sua própria percepção (CLARKE, 2002).

\subsection{O Feedback dos Informantes (validação comunicativa)}

O feedback dos informantes é mais um critério de validade e corresponde à confrontação com fontes e obtenção de sua concordância ou consentimento, sendo chamado de critério de validação comunicativa dos participantes. No entanto, o ator social não pode exercer a autoridade absoluta nas descrições e interpretações de sua ação, deixando, assim, o pesquisador como refém das afirmações e interpretações do ator social, comprometendo até a independência da pesquisa (MILES; HUBERMAN, 1994, GASKELL; BAUER, 2005).

Esse critério é conhecido também como sendo de confirmabilidade, que consiste na obtenção direta dos dados e geralmente repetidas afirmações do que o pesquisador tenha ouvido, visto, ou experienciado com relação ao fenômeno em estudo, esta prática inclui as auditagens e checagens confirmadas periodicamente pelo informante, além de sessões de feedback da pessoa investigada (LINCONL; GUBA, 1985; LEININGER, 1994).

A análise dos dados advindos das entrevistas num estudo qualitativo deverá ser realizada de acordo com as categorias explicativas decodificadas dos temas transcritos. Após uma leitura geral das enunciações naturais, será necessário realizar uma reconstrução dos relatos de acordo com os seus significados para o sujeito entrevistado, afim de se compreender em profundidade a factualidade 
dos dados. O quadro de sua experiência se expressará pela regularidade e pelo senso comum (LINCOLN; GUBA, 1985; MILES; HUBERMAN, 1994).

Para saber como os imigrantes se adaptam ao sistema de saúde pública de países do primeiro mundo, Goth e Berg (2011) tentaram entender qual a aceitação deles ao sistema de saúde público local destinado a imigrantes $e$ avaliar os obstáculos que enfrentavam ao utilizar esse sistema. Participaram do estudo, os lideres das 13 maiores organizações de imigrantes do país como informantes-chave. Para garantir a validação da pesquisa, os autores desenvolveram um estudo piloto prévio com um grupo pequeno de informantes para obterem feedbacks em todas as etapas do estudo. Como resultado, descobriram qual a real adequação dos imigrantes aos sistemas de saúde, principalmente no que diz respeito à comunicação médico-paciente, que variava de acordo com o tempo de permanência na Noruega, o país de origem do paciente, a razão para a migração, a intenção de estabelecer residência permanente no Noruega, proficiência da língua e compreensão das informações recebidas sobre o sistema de saúde.

\section{Considerações Finais}

Em suma, a proposta deste trabalho foi a de apresentar observações que manifestam a recomendação por pesquisas qualitativas que garantem resultados valiosos para o avanço desta tradição. No campo da Administração, são várias a possibilidades e até necessidades de se utilizar pesquisas qualitativas, sejam estas alinhadas à tradição posta, seja desenvolvida no seio de abordagens entendidas como pós-modernas (PEREIRA et al., 2007). Designs de pesquisa nesta perspectiva devem, portanto, ser um hábito prevalecente em termos de estudos e não a exceção.

Apesar de existirem defensores de que se deva descartar o termo validade em abordagens de paradigmas relativistas, acredita-se que vale mantê-lo, para garantir a circulação e a quebra de sinais clássicos que o codificam como atributo exclusivo de difusão da verdade. A validade é uma questão limite da pesquisa repetidamente revista, que não pode ser evitada e nem resolvida, constituindo-se, assim, em uma fértil obsessão na pesquisa, devido à sua natureza de dificuldade de tratamento adequado, por considerar-se que as condições 
da possibilidade da validade são também suas condições de impossibilidade (LATHER, 1993).

Um fato que Gaston Bachelard chama atenção é que a realidade nunca é simples e que na história da ciência as tentativas de se atingir a simplicidade acabam se demonstrando invariavelmente super simplificações e, então, a complexidade do real é afinal reconhecida (LECHTE, 2002). Portanto, nas ciências sociais aplicadas conceber o conhecimento válido como a convergência absoluta com a verdade do que ocorre nas relações dos atores sociais exige uma contínua reinterpretação sociocultural e histórica do sentido de sua ação na sociedade (LEININGER, 1994; SANTOS, 2009).

\section{Validity and Reliability in Qualitative Research in Management}

\section{Abstract}

The use of qualitative research is growing in the Management Academy. However, we understand that for its best use it is necessary to discuss validity and reliability principles. Thus, this text begins with a discussion concerning epistemological and ethical aspects associated with the use of qualitative research. Then, we argue the different types of validity and reliability criteria that are pertinent to qualitative research.Finally, these criteria are presented. This racionaleis applied to the manegement field. Concluding, we give reasons of the relevance of the present discussionand claim that itis paramount to the credibility of qualitative research in the management field, once dominated by the positivist paradigm.

Key words: Qualitative Research. Validity. Reliability. 


\section{Referências}

ANNA K.; DARYL M. An exploratory study looking at the relationship marketing techniques used in the music festival industry. Journal of Retail \& Leisure Property. Basingstoke/UK, v. 9, n. 5, p. 451-464, 2011.

BARGE, J. K.; OLIVER, C. Working with appreciation in managerial practice. Academy of Management Review, New York, NY/USA, v. 28, n. 1, p. 124-142, 2003.

BOEIRA, S. L.; VIEIRA, P. F. Estudos organizacionais: dilemas paradigmáticos e abertura interdisciplinar. In: GODOI, C. K.; BANDEIRA-DE-MELLO, R.; SILVA, A. B. (Org.). Pesquisa qualitativa em estudos organizacionais: paradigmas, estratégias e métodos. 2. ed. São Paulo: Saraiva, 2010.

BOOTH, C.; SEGON, M. Leadership and management development: an action research project. International Review of Business Research Papers, Melbourne/AUS, v. 5, n. 4, p. 102-11, 2009.

BRUYNE, P.; HERMAN, J.; SCHOUTHEETE, M. Dinâmica da pesquisa em ciênciassociais. 5. ed. Rio de Janeiro: Francisco Alves, 1991.

BRYMAN, A. Research methods and organization studies. London: Routledge, 2000.

BURNS, A. T; ACAR, W.; DATTA, P. A qualitative exploration of entrepreneurial knowledge transfers. Journal of Knowledge Management, Bingley/UK , v. 15, n. 2, p. 270-298, 2011.

CASTRO, C. M. A prática da pesquisa. São Paulo: Mcgrow-Hill do Brasil, 1977.

CHIZZOTTI, A. Pesquisa qualitativa em ciências humanas e sociais. Petrópolis: Vozes, 2006.

CLARKE, S. Learning from experience: psycho-social research methods in the social sciences. Qualitative Research, v. 2, n.2, p. 173-194, 2002.

CLEGG, S; HARDY, C. Introdução: organização e estudos organizacionais. In: CLEGG, S; HARDY, C.; NORD, V. (Ed.). Handbook de estudos organizacionais: modelos de análise e novas questões em estudos organizacionais. São Paulo: Atlas, 1999. 
CRESWELL, J. W. W. Projeto de pesquisa: métodos qualitativo, quantitativo e misto. 2. ed. Porto Alegre: Bookman, 2010.

DENZIN, N. K.; LINCOLN, Y. S. Introduction: the discipline and practice of qualitative research. In: DENZIN, N. K.; LINCOLN, Y. S. Handbook of qualitative research. 3. ed. Thousand Oaks: Sage Publications, 2005.

FLICK, U. Uma introdução à pesquisa qualitativa. 3. ed. Porto Alegre: Bookman, 2008.

GASKELL, G.; BAUER, M. W. Para uma prestação de contas pública: além da amostra, da fidedignidade e da validade. In: BAUER, M. W.; GASKELL, G. (Ed.). Pesquisa qualitativa com texto, imagem e som: um manual prático. 4. ed. Petrópolis: Vozes, 2005.

GIDENS, A. Capitalismo e moderna teoria social. 6. ed. Lisboa: Presença, 2000 .

GUBA, E. G.; LINCOLN, Y. S. Paradigmatic controversies, contradictions, and emerging confluences. In: DENZIN, N. K.; LINCOLN, Y. S. (Ed.). Handbook of qualitative research. 3. ed. Thousand Oaks: Sage Publications, 2005.

GODOI, C. K.; BALSINI, C. P. V. A pesquisa qualitativa nos estudos organizacionais brasileiros: uma análise bibliométrica. In: GODOI, C., K.; BANDEIRA-DE-MELLO, R.;SILVA, A. B. (Ed.). Pesquisa qualitativa em estudos organizacionais: paradigmas, estratégias e métodos. 2. ed. São Paulo: Saraiva, 2006.

HOLSTEIN, J. A.; GUBRIUM, J. F. Interpretative practice and social action. In: DENZIN, N. K.; LINCOLN, Y. S. (Ed.). Handbook of qualitative research. 3. ed. Thousand Oaks: Sage Publications, 2005.

JICK, T. D. Mixing qualitative and quantitative methods: triangulation in action. Administrative Science Quarterly, London/UK, v. 24, n. 4, p. 602-611, 1979.

JOY, A.et al. Writing it up, writing it down: being reflexive in accounts of consumer behavior. In: BELK, R. (Ed.). Handbook of qualitative research methods in Marketing. Edward Elgar: Northampton, 2006, p. 345-360.

KIRK, J.; MILLER, M. L. Reliability and validity in qualitative research. Thousand Oaks: Sage Publications, 1986. 
LATHER, P. Fertile obsersion: validity after post structuralism. Sociological Quarterly, v. 34, n. 4, p. 673-693, 1993.

LEÃO, A. L. M. S.; MELLO, S. C. B.; VIEIRA, R. S. G. O papel da teoria no método de pesquisa em Administração. Revista Organizações em Contexto, São Paulo, v. 5 , n. 10, p. 1-16, 2009.

LECHTE, J. 50 pensadores contemporâneos essenciais: do estruturalismo à pós-modernidade. Rio Janeiro: Difel, 2002.

LEININGER, M. Evaluation criteria and critique of qualitative research studies. In: MORSE, J. (Org.). Critical issues in qualitative research methods. London: Sage, 1994.

LINCONL, Y. S.; GUBA, E. G. Naturalistic inquiry. London: Sage Publications, 1985.

MARKUS, L. H.; COOPER-THOMAS, H. D.; ALLPRESS, K. N. Confounded by competencies? Anevaluation of the evolution and use of competency models. Journal of Psychology, Philadelphia, PA/USA, v. 34, n. 2, p. 117-126, 2005.

MERRIAM, S. B. Qualitative research and case study applications in education: revised and expanded from case study research in education. 2.ed. San Francisco: Jossey-Bass Education Series and The Josey-Bass Higher Education Series, 1998.

MILES, M. B.; HUBERMAN, A. M. Qualitative data analysis: an expanded source book. 2. ed. London: Sage Publications, 1994.

MINAYO, M. C. S. O desafio do conhecimento: pesquisa qualitativa em saúde. 12. ed. São Paulo: Hucitec, 2010.

MUNCK, L.; MUNCK, M. G. M; SOUZA, R. B. Gestão de pessoas por competências: análise de repercussões dez anos pós-implantação. Revista de Administração Mackenzie, São Paulo, v. 12, n. 1, p. 4-52, 2011.

OGBOR, J. Mythicizing and reification in entrepreneurial discourse ideology-critique of entrepreneurial studies. Journal of Management Studies, Malden, MA/USA, v. 37 , n. 5, p.605-635, 2000. 
OLIVA, A. Verificacionismo: critério de cientificidade ou crítica à ideologia? In: OLIVA, A. Epistemologia: a cientificidade em questão. Campinas: Papirus, 1990.

PATTON, M. Q. Qualitative research and evaluation methods. 3. ed. London: Sage Publications, 2002.

PEREIRA, M. C.; MUNIZ, M. M. J.; LIMA, J. B. Foucault e estudos organizacionais: ampliando as possibilidades de análise. Revista de Ciências da Administração, v. 9, n. 17, p. 113-133, jan./abr. 2007.

POPPER, K. A lógica da pesquisa científica. 6. ed. São Paulo: Cultrix, 2000.

RABECHINI JUNIOR, R. et al. A organização da atividade de gerenciamento de projetos: os nexos com competências e estrutura. Gestão e Produção, São Carlos, v. 18, n. 2, p. 409-424, 2011.

RICE, M.P. Co-production of business assistance in business incubators: an explanatory study. Journal of Business Venturing, Kidlington/UK, v.17, p. 163187, 2002.

RISJORD, M.; MOLONEY, M.; DUNBAR, D. Methodological triangulation in nursing research. Philosophyofthe Social Sciences, v. 31, n. 1, p. 40-59, 2001.

SANTOS, D. F. L. Possibilidades da hermenêutica na Administração. Revista de Ciências da Administração, Florianópolis, v. 11, n. 23, p. 113-133, jan./abr. 2009.

TUZZO, S. A.; MAINIERI, T. Pesquisa empírica em comunicação organizacional e relações públicas: proposta metodológica e olhar sobre a prática de assessorias de comunicação em Goiás. Revista Brasileira de Ciências da Comunicação, São Paulo, v. 34, n.1, p. 233-252, 2011.

WIESENFELD, E. Between prescription and action: the gap between the theory and practice of qualitative inquiries. Forum of Qualitative Social Research, Berlin/ DE, v. 1, n. 2, 2000. 